\title{
Large scale semi-automatic detection of forest roads from low density LiDAR data on steep terrain in Northern Spain
}

\author{
Covadonga Prendes ${ }^{(1)}$, \\ Sandra Buján (2), \\ Celestino Ordoñez ${ }^{(3)}$, \\ Elena Canga ${ }^{(1)}$
}

\begin{abstract}
While forest roads are important to forest managers in terms of facilitating the exploitation of wood and timber, their role is far more multifunctional. They permit access to emergency services in the case of forest fires as well as acting as fire breaks, enhance biodiversity, and provide access to the public to enjoy recreational activities. Detailed maps of forest roads are an essential tool for better and more timely forest management and automatic/semi-automatic tools allow not only the creation of forest road databases, but also enable these to be updated. In Spain, LiDAR data for the entire national territory is freely available, and the capture of higher density data is planned in the next few years. As such, the development of a forest road detection methodology based on LiDAR data would allow maps of all forest roads to be developed and regularly updated. The general objective of this work was to establish a low density LiDAR data-based methodology for the semi-automatic detection of the centerline of forest roads on steep terrain with various types of canopy cover. Intensity and slope images were generated using the currently available LiDAR data of the study area $\left(0.5\right.$ points $\left.\mathrm{m}^{-2}\right)$. Two image classification approaches were evaluated: pixel-based and object-oriented classification (OBIA). The LiDAR-derived centerlines obtained with the two approaches were compared with the real centerlines which had previously been digitized in the field. The road width, type of surface and type of vegetation cover were also recorded. The effectiveness of the two approaches was evaluated through three quality indicators: correctness, completeness and quality. In addition, the accuracy of the LiDAR-derived centerlines was also evaluated by combining GIS analysis and statistical methods. The pixel-based approach obtained higher values than OBIA for two of the three quality measures (correctness: $93 \%$ compared to $90 \%$; and quality: $60 \%$ compared to $56 \%$ ) as well as in terms of positional accuracy $( \pm \mathbf{5 . 5} \mathrm{m}$ vs. \pm 6.8 for OBIA). The results obtained in this study demonstrate that producing road maps is among the most valuable and easily attainable products of LiDAR data analysis.
\end{abstract}

Keywords: GIS, Pixel-based Classification, OBIA, Quality Measures, Forest Roads Network, Accuracy Assessment

Forest road networks provide connections between different forested areas as well as to the primary road network, thereby providing access to recreational and educational activities for the public, as well as playing an important role in fire-fighting support (both preventative in terms of for-
(1) CETEMAS, Centro Tecnológico y Forestal de la Madera, Área de Desarrollo Forestal Sostenible. Pumarabule, Carbayín Bajo s/n 33936 Siero (Spain); (2) Laboratorio do Territorio (LaboraTe), Universidad de Santiago de Compostela. C/ Benigno Ledo Campus Universitario 27002 Lugo (Spain); (3) Departamento de Explotación de Minas, Grupo de Investigación en Geomática y Computación Gráfica (GEOGRAPH), Universidad de Oviedo, 33004 Oviedo (Spain)

@ Covadonga Prendes (cprendes@cetemas.es)

Received: Nov 05, 2018 - Accepted: Apr 15, 2019

Citation: Prendes C, Buján S, Ordoñez C, Canga E (2019). Large scale semi-automatic detection of forest roads from low density LiDAR data on steep terrain in Northern Spain. iForest 12: 366-374. - doi: 10.3832/ifor2989-012 [online 2019-07-05]

Communicated by: Agostino Ferrara est roads acting as firebreaks and in terms of access to emergency services in the case of forest fires) and logging activities (Grigolato et al. 2013). Despite this, it must also be acknowledged that forest roads can also have negative impacts on the health of ecosystems, mainly in relation to hydrology and habitat disturbance (Sherba et al. 2014).

From the point of view of forestry production, in order to carry out profitable and sustainable forest management it is crucial to create management tools that help to establish the availability of resources and the economic viability of their use, so that logging costs can be minimized. To efficiently calculate transport costs (including hauling and road transport phases), it is essential to have access to information on the extent and conditions of the current road forest network. The role of GIS (Geographical Information Systems) in this respect is increasingly important and such data can provide a solid framework for forestry companies seeking to improve 
their logistics, as it allows the optimization of transport planning according to various criteria (Arora \& Pandey 2011). For all the reasons mentioned above, it is essential to develop automatic/semi-automatic tools to enable forest roads and timber extraction routes mapping as well as their periodic updating.

In general terms, the task of detecting and extracting the course of roads from digital information has been addressed in a number of ways over the years: photointerpretation and manual digitization, the integration of cartography from different sources, data capture in the field, and data capture from remote sensors (Kiss et al. 2016). In the case of spatial data sources (aerial photographs or satellite images), the application of image classification methods for road extraction has been studied for more than twenty years (Gruen \& Li 1997, Heipke et al. 1997, Dial et al. 2001, Narwade \& Musande 2014, Kiss et al. 2016). However, these methodologies all suffer similar problems with respect to field data collection in relation to forest roads: (i) the high cost of data acquisition in relation to the relatively small areas that can be mapped; (ii) interference of GPS signal; and (iii) occlusions due to the presence of trees (Abdi et al. 2012). With the techniques of photointerpretation and remote sensing the main drawbacks are the resolution of the produced images, which in some cases is not sufficient for the detection of very narrow carriageways, and difficulty in obtaining information from below tree covered areas, which leads to discontinuities in the centerlines of the forest roads identified (Sherba et al. 2014).

Within this unfavorable context for the application of remote sensing images in forest areas, LiDAR technology brought about a great advance in the automatic detection and updating of forest road networks, because it provides accurate measurements of ground elevation, which allows high resolution topographic mapping, even under dense canopy cover (White et al. 2010). As such, forest roads are easy to identify as they are on ground level, have a different topographic profile to other environments (planarity of the road surface) and present high spectral contrast with the otherwise undisturbed environment. These attributes can be exploited through the analysis of LiDAR point clouds and LiDAR intensity values (Buján et al. 2012). Various authors have already harnessed the great potential of LiDAR data for forest road detection and used airborne laser scanning devices in studies using a variety of approaches. In terms of how roads are represented in the final data collected, remote sensing methods can be grouped into those that produce two-dimensional elements (road segments) and those that produce one-dimensional lines (road centerline - Clode et al. 2007). Typically, research in the first group uses high resolution/density data and allows the detection of both the length and width of forest roads. Some examples are the method based on standard edge extraction algorithms from the slope map (Clode et al. 2007), the objectoriented classification developed by Sherba et al. (2014) and the Support Vector Machine used by Azizi et al. (2014). In contrast, studies in the second group use low resolution/density data which allows the detection of the road centerline, and include, for example, the dynamic programming method proposed by Saito et al. (2013).

In general, while Saito et al. (2013) achieved good results in terms of number of roads detected and the accuracy of their centerlines with high or medium density data, all methods encounter difficulties in areas of dense canopy covers, and where there is a high degree of slope and the density of ground points on roads obscured by dense vegetation will be much lower. Thus, methods that are based on the assumption that roads will have a higher density of ground points than forested areas, such as the one developed by Beck et al. (2015), may fail in detecting roads lined by dense tree cover. On the other hand, on steep terrain, the filtering algorithms have problems distinguishing which elevation is actually the ground level. Since the methods of forest road extraction developed to date (Clode et al. 2007, Azizi et al. 2014) have used DTMs (Digital Terrain Models), which are based on ground point information, this entails a challenge for forest road detection using LiDAR data. In addition, the limited availability of LiDAR data hampers the development of comprehensive forest road network maps, since data acquisition is one of the most expensive steps in remote sensing studies (González-Ferreiro et al. 2012).

In this respect, Spain is one of the few countries in the world to have a National Plan for Territory Observation (LiDAR$\mathrm{PNOA}^{\odot}$ National Geographic Institute of Spain) which ensures the capture of LiDAR data at various times across the whole of its territory. At the moment, data from only one flight (between 2008 and 2015, depending on the region) is available for civil use, but more flights to update the current data are expected to take place in the next couple of years. While this data has one main drawback - the low cloud point density used for the vast majority of the territory (only 0.5 points $\mathrm{m}^{-2}$ ) - this is counterbalanced by the fact that data is available for the whole national territory at no cost. In addition, the fact that the data is to be updated periodically with further flights means that there is an ongoing source of date to use to ensure that the mapping of the forest road network is regularly brought up to date.

Despite the easily accessible availability of LiDAR data and the great potential that this technology has shown in various studies, in Spain no great efforts have been made to build a public cartography of for- est road networks. This fact is especially worrisome in the northern part of the country (specifically in Asturias) where according to the Spanish National Forest Inventory (DGDRPF 2012), 73\% of the total surface is forested and the potential for wood production is extremely high. Within this area, however, environment conditions are difficult, i.e., very steep orography ( $47 \%$ of the land covered by trees has a slope between 30 and $60 \%$ while $5 \%$ has more than 60\%) and densely planted forest stands.

In view of the above, this study aims to test the hypothesis that it possible to use low-density LiDAR data to semi-automatically detect and extract forest roads and that this is a more efficient alternative than manual digitization. The study aims to design a semi-automatic methodology to obtain the centerline of forest roads from low density LiDAR data in a steep forested environment. Two approaches have been evaluated: a pixel-based methodology and one which is object-oriented (OBIA). In addition, the influence of the characteristics of forest roads (width and type of road surface) and the surrounding vegetation (type of canopy cover bordering the road) on the results of these two types of semi-automated detection was also analyzed. Steep environments are acknowledged to be an extremely difficult context for forest management (White et al. 2010) and to obtain accurate information about forest road networks, thus a method of road detection that is effective and efficient in these conditions is likely to be easily applied in less challenging circumstances.

\section{Material and methods}

\section{Study area}

The study area is located in Asturias, a mountainous region situated in the northwest of Spain. A state-owned forest of 178.77 ha was chosen as a pilot area because it is a representative sample of the type of forests found in the region, which are generally characterized by steep slopes and a variety of species. Elevation range is between 36 and 335 meters a.s.l. and over half the area (55.7\%) has a slope ranging between $31 \%$ and $60 \%$, while $20.7 \%$ is above $60 \%$. These characteristics provide a challenging though realistic environment where the detection methodologies of this study could be assessed.

The study area incorporates a number of stand types. There are pure stands of Pinus pinaster Ait. (both mature stands - henceforth: "pine" - and younger reforested areas under 5 years old - henceforth: "reforested"), along with mixed stands of broadleaved species which are dominated by Castanea sativa Mill., but also include Quercus robur L. and Eucalyptus globulus Labill. (henceforth: "broadleaved"). The distribution of the different stand types across the study area is shown in Fig. $1 \mathrm{~A}$. 

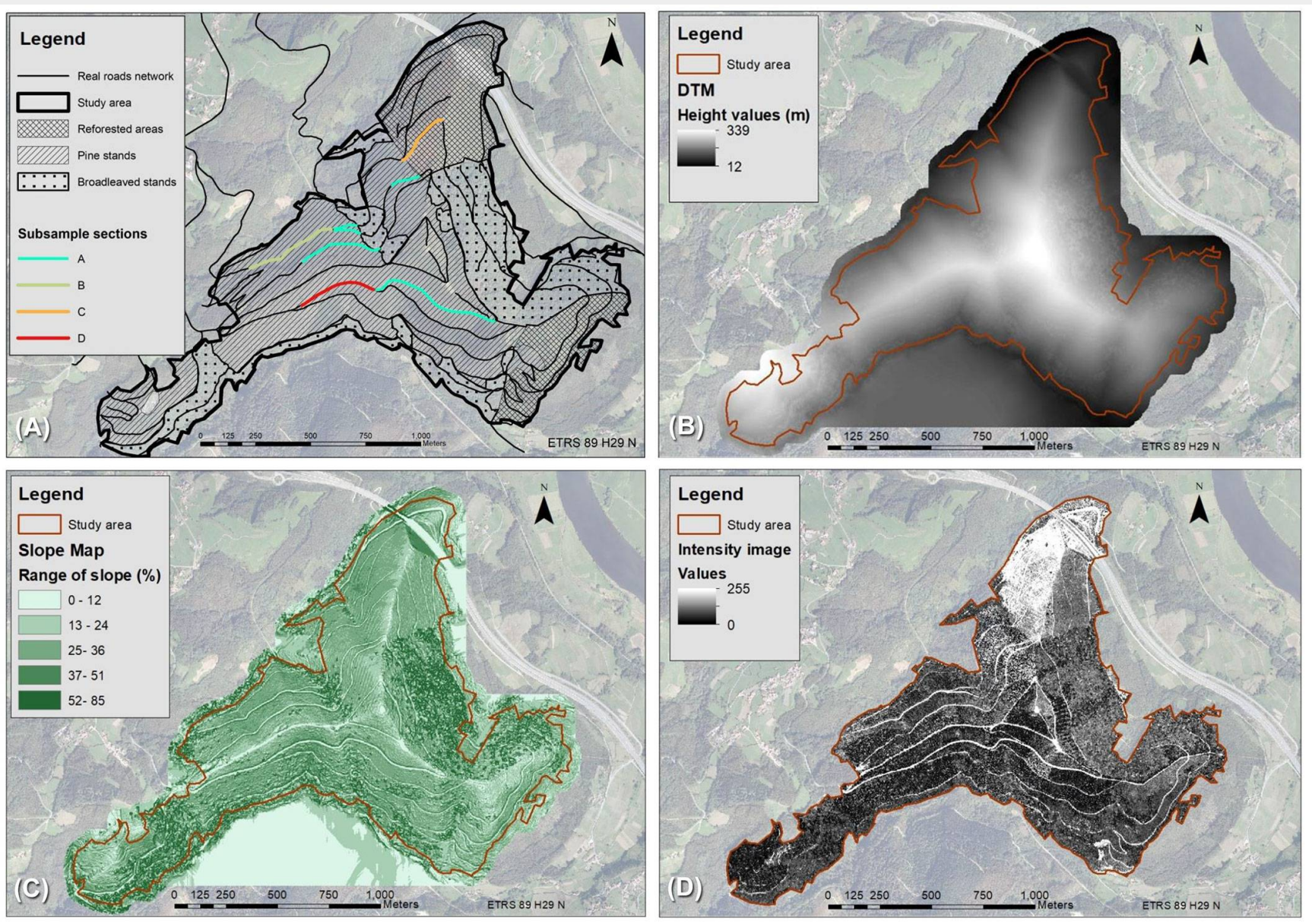

Fig. 1 - (A) Distribution of different stand types across the study area; (B) DTM resulting from the validation step; (C) Slope map resulting from the DTM; (D) Intensity image of the study area.

\section{Data}

LiDAR data for the study area was captured under the framework of the PNOA (LIDAR-PNOA 2012) during the summer of 2012. Average cloud point density was 0.5 points $\mathrm{m}^{-2}$ and the altimetric accuracy of LiDAR data was around $20 \mathrm{~cm}$.

In order to test the accuracy of the LiDAR detection of forest roads, the real centerlines of the forest roads network in the study area were collected in the field during the summer of 2013 using a GPS Trimble Explorer $\mathrm{XH}^{\mathrm{TM}}$ (Trimble, Sunnyvale, $\mathrm{CA}$, USA) with submetric accuracy. This data was collected in shape format, whereby the lines defining the centerlines of forest roads are associated with a database which records their main attributes (width and type of road surface and surrounding vegetation).

A further set of field data was also captured using a GPS model with centimetric accuracy (TOPCON GR-3 ${ }^{\mathrm{TM}}$, TopCon Positioning Systems Inc., Livermore, CA, USA) which was then used to assess the accuracy of the LiDAR-derived products to be used in the analyses. Firstly, to assess the accuracy of the LiDAR-derived DTMs, 55 ground points were measured in the field which were located in areas of varying degrees of slope and different types of vege- tation to ensure variability in these factors was covered. Secondly, to evaluate the planimetric accuracy of the LiDAR-derived centerlines obtained with the two approaches, a subsample was selected consisting of four sections of forest roads (A, $B, C$ and $D$ ), each with a different type of road surface, and sometimes differing in road width and surrounding vegetation (Tab. 1). The field-survey centerline of each section was digitized for use as a positional reference.

\section{LiDAR data processing}

For the detection of the forest road network two LiDAR inputs were used: slope map and intensity image. The intensity image enables covered areas to be distinguished from uncovered areas, and the slope map provides information about ter- rain morphology (Sherba et al. 2014).

In order to get an accurate slope map, the first step was to obtain a DTM of the study area. The procedure to obtain a DTM from LiDAR data involves two differentiated steps: the separation of the LiDAR point cloud into those points belonging to the ground and those belonging to tree cover through a filtering process; and the subsequent interpolation of ground points to generate a continuous surface that comprises the DTM. A two-step validation process (see below) was carried out so that the best combination of parameters in each case was established and then used to produce the final DTM.

\section{Filtering quality assessment}

Firstly, the filtering of ground points was conducted using the "GroundFilter" func-

Tab. 1 - Characteristics of the subsample sections.

\begin{tabular}{cclcl}
\hline Section & $\begin{array}{c}\text { Length } \\
(\mathrm{m})\end{array}$ & $\begin{array}{l}\text { Road } \\
\text { surface }\end{array}$ & $\begin{array}{c}\text { Road width } \\
(\mathrm{m})\end{array}$ & $\begin{array}{l}\text { Surrounding } \\
\text { vegetation }\end{array}$ \\
\hline A & 994.3 & Aggregate & $2-4$ & Pine \\
\hline B & 809.2 & Dirt & $2-4$ & Pine \\
\hline C & 266.1 & Rock & $2-4$ & Reforested \\
D & 359.8 & Aggregate & $>4$ & Pine \\
\hline
\end{tabular}




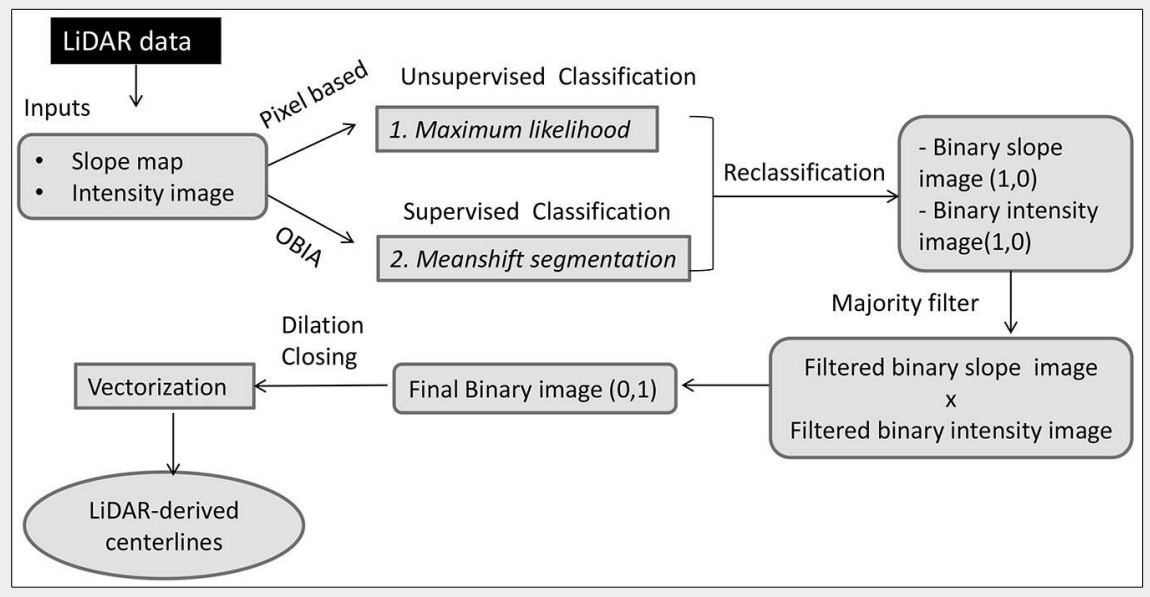

Fig. 2 - The workflow followed to obtain LiDAR-derived centerlines.

tion (an adaptation of the IRI filter by Kraus \& Pfeifer (1998) included in the software FUSION ver. 3.5 (McGauhey 2009). To find the parameters of the "GroundFilter" function $(g, w)$ showing the best performance, 36 combinations were tested in four control areas (each of around 0.5 ha) having specific characteristics making the analysis difficult, such as steep terrain, dense vegetation, etc.). The ranges for each parameter were as follows: $g \in[-2,-1]$ at intervals of $0.5 \mathrm{~m}$ and $w \in[1.5,3.5]$ at intervals of $1 \mathrm{~m}$. Within the control areas, LiDAR datasets were manually classified as ground and not ground points to obtain a reference dataset for comparison. The validation of the filtering process was carried out following the methodology outlined in Sithole \& Vosselman (2004) and Hu et al. (2014). The filtering parameters finally selected were $g=-1.5$ and $w=3.5$.

\section{Assessment of LiDAR DTM accuracy}

In order to assess the accuracy of the $\mathrm{Li}$ DAR DTM, a robust statistical error validation process (Höhle \& Höhle 2009) was carried out after generating the candidate DTMs with the various combinations of filter parameters. To do this, the 55 GPS ground captured in the field (see above) were used as control points. All the candidate DTMs had resolution of $2 \times 2 \mathrm{~m}$ to guarantee that there was at least one point within each pixel.

The DTM which obtained the best results following the two validation steps (Fig. 1B) was selected to generate the slope map (Fig. 1C) which then served as input for the detection approaches.

Due to the fact that intensity values are influenced by terrain, flight and sensor characteristics, as well as by atmospheric conditions (Song \& Civco 2004), intensity values need to be corrected. The only data available for this is the average flight height, which can be used to normalize the range, as per the methodology proposed by García et al. (2010). Based on the normalized intensity values of the LiDAR data, an intensity image was created for a cell size of $2 \mathrm{~m}$ (Fig. 1D).

Forest roads detection workflow: pixelbased vs. object-oriented classification (OBIA)

To extract the forest roads from the $\mathrm{Li}$ DAR data, the workflow shown in Fig. 2 was followed using two different approaches: a pixel-based classification and an OBIA one. In both cases the intensity image and the slope map were the inputs of the procedure.

In the first approach, the normalized intensity image and the slope map were subjected to a pixel-level classification using the Maximum Likelihood (ML) algorithm. This method considers that digital levels within each class fit a normal distribution such that each classification category can be described by a probability function deduced from its mean vector and its matrix of variance-covariance. The calculation was performed for all classification categories involved, each pixel being assigned to the category that maximized the probability function (Edgeworth 1908).

In the second approach, the normalized intensity image and the slope map were subjected to an object-oriented unsupervised classification. The algorithm for the segmentation of both images was Meanshift (MS) segmentation (Comaniciu \& Meer 2002). This algorithm identifies features or segments in an image by grouping together adjacent pixels that have similar spectral characteristics. The amount of spatial and spectral smoothing to assist in the derivation of features of interest can be controlled. Unlike with the ML algorithm, no assumption about probability distributions is made.

The intensity images and slope maps from the two different classification processes used were then reclassified, based on a manual visual analysis, to obtain a binary image - "forest roads" (1) and "not forest roads" (0) - for both slope and intensity.
These binary slope and intensity images were then refined using a majority filter which removes single pixels or noise and replaces the cell(s) depending on the categories of the neighboring cells. After that, the two binary images from each approach were combined by multiplication to obtain one single final binary image, also classified into o (not road) or 1 (roads), for the pixel approach and one for the OBIA approach.

This final binary image resulting from each approach was then subjected to a second refining process in order to remove noise and to achieve continuity within category 1 "forest roads" (dilation and closing filter). The final step was automatic vectorization, a technique which converts raster data into vector entities (Mena 2006). Using this technique, a vector file which defined the centerline of the forest roads with a line was obtained (LiDAR-derived centerlines). Visual inspection of these $\mathrm{Li}$ DAR-derived centerlines was carried out to ascertain the threshold for noise (established as being $25 \mathrm{~m}$ ), and all lines not meeting this threshold were removed to reduce noise.

The workflow explained above was automatized with the help of GIS software that uses a Model Builder.

\section{Analysis of results and accuracy}

assessment

\section{Overall assessment using the quality} measures

The results from the two approaches were assessed using the methodology described by Azizi et al. (2014), i.e., the LiDARderived centerlines from each approach were compared with the real centerline measured in the field. In order to do this, the real centerline was divided into 500 segments of equal length $(48 \mathrm{~m})$ and a 10 meter buffer was built around it (i.e., the area of influence of the forest road). In this way, all LiDAR-derived centerlines located completely within the buffer zone were considered to be detected ("True Positives", TP - Fig. 3A) and those only partly in the buffer zone were designated as "False positives" (FP - Fig. 3B), while those not identified were classified as "False Negatives" (FN - Fig. 3C)

From the number of TP, FN and FP found, the quality measures were calculated, as described in the work of Wiedemann et al. (1998a), i.e., completeness (eqn. 1), correctness (eqn. 2 ) and quality (eqn. 3):

$$
\begin{aligned}
& \text { Completeness }=\frac{T P}{(T P+F N)} \\
& \text { Correctness }=\frac{T P}{(T P+F P)} \\
& \text { Quality }=\frac{T P}{(T P+F N+F P)}
\end{aligned}
$$

Completeness is the percentage of the reference data (in this case the field data) explained by the extracted data, while correctness represents the percentage of cor- 
rectly extracted road data. Quality is a more general measure of the final result which combines completeness and correctness into a single measurement. The maximum value for each of the quality measures is $1(100 \%)$.

\section{Influence of the characteristics of forest roads and the surrounding vegetation in the detection}

An analysis of variance (ANOVA) was performed to evaluate the influence of various factors on the detection of forest roads, particularly on the quality measures: completeness, correctness and quality. The factors analyzed were: surrounding vegetation type, road surface and road width. All possible combinations of the three factors were considered resulting in a forest road classification of 25 classes. In addition, the influence of the two different approaches used in the detection was also evaluated.

\section{Assessment of accuracy of LiDAR-derived centerlines}

Besides estimating the quality of the two methods tested in terms of completeness correctness and quality, the positional accuracy of the centerlines of the LiDAR-derived centerlines was compared to the field-survey centerline of sections $A, B, C$ and $D$ using a simple method proposed by Goodchild \& Hunter (1997). This method is based on the generation of buffers of differing width around the field-survey centerline, after which the percentage of $\mathrm{Li}$ DAR-derived centerlines inside each buffer width is calculated. To this end, 20 buffers, at half meter intervals from 0.5 to $10 \mathrm{~m}$ were created. Based on the results obtained with the two different approaches, a plot of the percentage of LiDAR-derived centerlines lying within the buffer vs. the buffer width was created and the buffer width required to accommodate $95 \%$ of the field-survey centerlines was used as a measure of overall positional accuracy (Goodchild \& Hunter 1997, Tveite 1999).

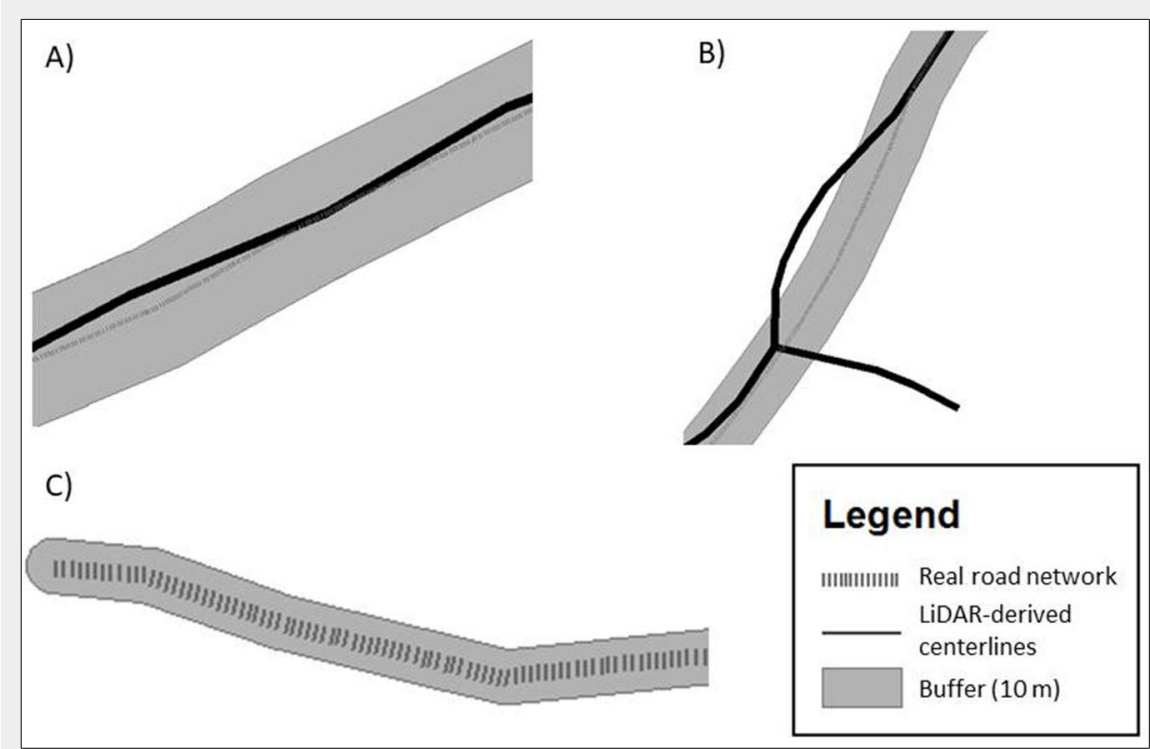

Fig. 3 - Measures used to calculate the quality measures in forest road detection for the two assessed methodologies. (A) "True Positive" (TP): LiDAR-derived centerlines that are real forest roads. (B) "False Positive" (FP): LiDAR-derived centerlines that do not follow the real road. (C) "False Negative" (FN): forest roads not identified.

\section{Results and discussion}

\section{Overall Assessment of the two} approaches (Pixels vs. OBIA)

The LiDAR-derived centerlines obtained with each of the two approaches are shown graphically in Fig. 4.

Tab. 2 shows the average values of the quality measures obtained for each of the two approaches assessed in this study.

In terms of completeness, the value obtained in the two approaches was similar, meaning that total percentage of the forest roads network detected with both approaches is around $60-65 \%$. The correctness value was also very similar for both, and indicates that around $90 \%$ of the $\mathrm{Li}$ DAR-derived centerlines detected automatically represented real roads. Commission error in both cases was therefore low. Quality provides a more global measure of reliability, since it takes into account both the completeness and the correctness of the extracted data (Wiedemann et al. 1998b). The quality value in the pixelbased approach was $4 \%$ higher than with OBIA ( 60 and $56 \%$, respectively). Thus it can be concluded that, as a whole, the pixelbased classification yields slightly better results than the object-oriented one, particularly in terms of quality and completeness.

Influence of the characteristics of forest roads and the surrounding vegetation on detection

Based on the real centerlines collected in the field, the total length of the forest roads network is $24 \mathrm{~km}, 70 \%$ of which were identified in the visual inspection as being in good condition. In relation to road width, the vast majority of forest roads (75\%) were wide enough to allow for the

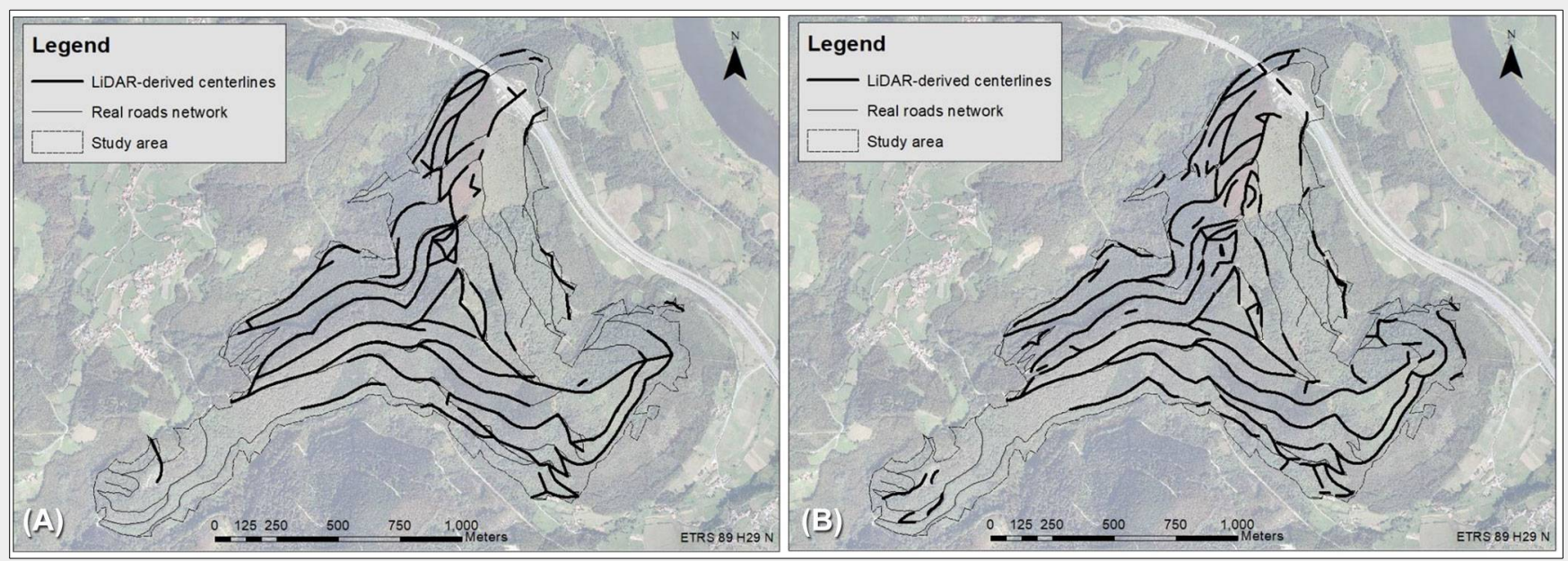

Fig. 4 - Forest road network obtained with the two detection approaches: pixel-based (A) and OBIA (B). 
Tab. 2 - Quality measures obtained for the two detection approaches: pixel-based (Pixels) and OBIA.

\begin{tabular}{cccc}
\hline Approach & Completeness & Correctness & Quality \\
\hline Pixels & 0.65 & 0.90 & 0.60 \\
OBIA & 0.59 & 0.93 & 0.56 \\
\hline
\end{tabular}

Tab. 3 - Results of Analysis of Variance (ANOVA) to quantify the influence of the factors on the quality measures.

\begin{tabular}{lcccccccc}
\hline \multirow{2}{*}{ Metric } & \multicolumn{2}{c}{ Vegetation } & \multicolumn{2}{c}{ Road surface } & \multicolumn{2}{c}{ Methodology } & \multicolumn{2}{c}{ Road width } \\
\cline { 2 - 9 } & F & prob & F & prob & F & prob & F & prob \\
\hline Completeness & 7.92 & 0.0002 & 1.27 & 0.2967 & 0.25 & 0.6205 & 3.97 & 0.0258 \\
\hline Correctness & 6.64 & 0.0008 & 0.98 & 0.4123 & 0.54 & 0.4667 & 2.86 & 0.0677 \\
Quality & 7.49 & 0.0004 & 1.14 & 0.3453 & 0.44 & 0.5120 & 4.8 & 0.0129 \\
\hline
\end{tabular}

circulation of forestry machinery $(2.5 \mathrm{~m}$ or more).

In this scenario, and despite the heterogeneity of the study area which presented great differences in terms of orography, types of surrounding vegetation and road surface, both approaches were able to detect and draw the centerline of the principal forest roads. Both approaches were particularly effective in areas where road width was $>2.5 \mathrm{~m}$ and when roads were not occluded by vegetation, conditions particularly prevalent in the southern part of the study area (Fig. 4A, Fig. 4B).

Tab. 3 reports the results of the ANOVA performed on the quality measures evaluated and shows that there were no statistically significant differences between group averages for the two methodologies used in the detection (Methodology column). However, significant statistical differences were found between all quality measures in the case of vegetation type, and between completeness and quality averages in the case of road width.

The strongest influence on detection was that of the surrounding vegetation, as can be observed in Fig. 5 which graphically represents the relationship between the valclassification. It can clearly be observed to have a role. However, this is more diffifact that the open space between forest struction will get smaller over time due to detection rates in broadleaved stands. ues of the quality measures and the surrounding vegetation for the pixel-based that all values except correctness are lower for forest roads through broadleaved stands. This suggests that the pixelbased classification works better in areas with wide forest roads which are not surrounded by broadleaved species. Forest road width itself may not be the only factor influencing forest road detection, the width of the belt of forest cleared in order to construct the carriageway is also likely cult to quantify with LiDAR technology, and was not taken into account for the purpose of this study. Another issue that should be taken into consideration is the stands due to the forest road and its conthe growth of tree crowns along the stand edge close to the road, which at a certain point may begin to occlude the road itself. In this respect, broadleaved species have globular thick crowns which will generally occupy more space than conifers, and this may have contributed to the lower road

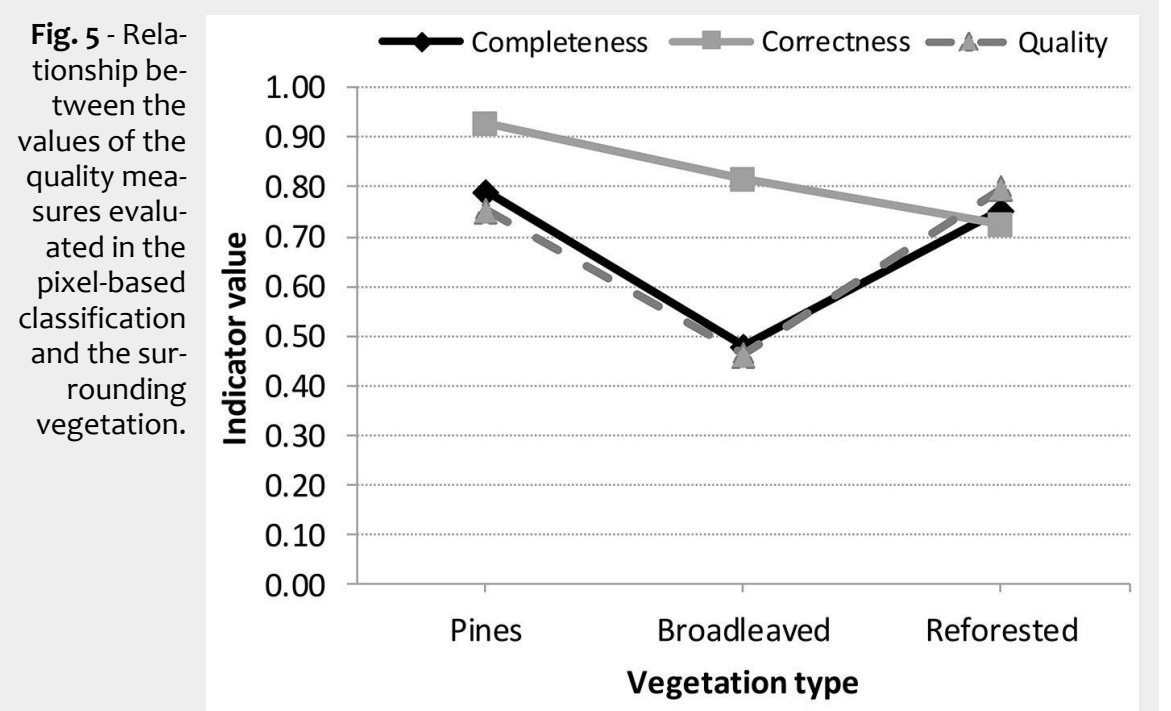

Comparing these results with those of other authors, a study carried out by Azizi et al. (2014) in a forested area using LiDAR data with a density of 4 points $\mathrm{m}^{-2}$ found values of completeness, correctness and quality of $63.02 \%, 75.07 \%$ and $52.17 \%$, respectively. In their case, they used input data (Digital Surface Model and intensity image) from an SVM (Support Vector Machine) classification. The values they found are quite close to those obtained from the pixel-based classification presented here, especially in terms of quality, despite the data used in the present study being of much lower density, only 0.5 points $\mathrm{m}^{-2}$. One reason for this may be that in the work of Azizi et al. (2014), 80\% of its forest roads were under tree cover, which negatively influenced the detection in terms of the low number of ground points resulting in a DTM of 1 meter of resolution. Another study by Sherba et al. (2014) used a fully automated object-based classification, which performed well with a total accuracy of $86 \%$, a considerable improvement over the pixel-based unsupervised classification used for comparison, which resulted in a road classification accuracy of only $77 \%$. However, it should be taken into account that these authors were working with data of 6 points $\mathrm{m}^{-2}$ and an average road width of 4 meters. In fact they also assessed the influence on the quality of detection of artificially reducing the point cloud density. They found that changing the average point density from 1.2 points $\mathrm{m}^{-2}$ to 0.06 points $\mathrm{m}^{-2}$ resulted in total accuracy falling from close to $70 \%$ to below $50 \%$. Determining the optimum data density for forest road detection is challenging, and although all authors agree that the higher the better (James et al. 2007, Kiss et al. 2016), several studies demonstrated that road curves and slope can be assessed from even very sparse (1.12 points $\mathrm{m}^{-2}$ ) airborne scanning data (Craven \& Wing 2014). However, in any given area, factors such as road width, type of road surface, surrounding vegetation, etc. will vary, making it difficult to draw definitive conclusions from comparisons between studies.

In the future, in line with the PNOA, when LiDAR data of higher density will be captured for the whole of Spain, the results obtained with the methods detailed in this work will be improved in terms of both quality and positional accuracy. Until such data will be available, the approaches described here can serve to provide the first step in developing a large-scale national database of forest roads networks.

Two limitations of the approaches used here must, however, be recognized. These pertain to forest roads width and the type of vegetation bordering forest roads. The majority of the forest roads that were not detected by either approach are narrow and, on the whole, surrounded by dense broadleaved vegetation. The influence of the type of vegetation is made especially evident by the fact that the centerline of 
Fig. 6 - Percentage of LiDAR-derived centerline lying within the buffer as a function of buffer width using pixel-based approach (A) and OBIA approach (B).
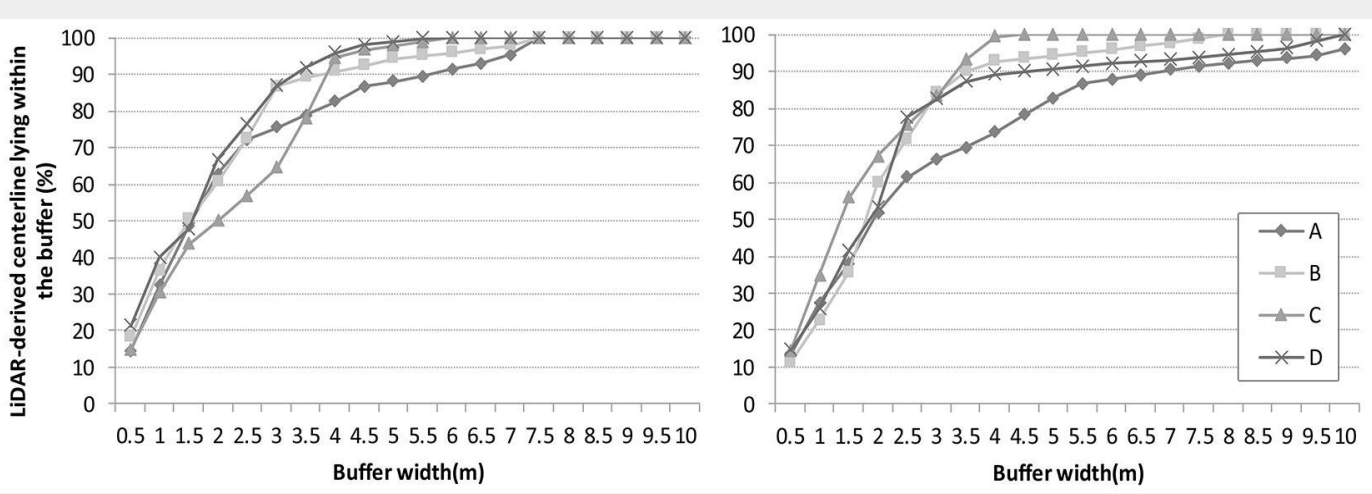

forest roads running through broadleaved stands is at times completely occluded, thus making road detection exceedingly difficult. It should be noted that the LiDAR data used in this study was captured during summer, when broadleaved canopies were in full leaf. Thus, the laser beam cannot penetrate through the dense canopy to the ground, resulting in a lower quality DTM not representing the shape of the land surface, but rather of the vegetation. In the case of intensity image, the leafy areas appear very dark because they represent the highest points of the vegetation, especially in those areas where the high canopy density hinders the centerline of a forest road to be detected from the air, or is completely masked. In areas where there are two types of vegetation stand adjacent to each other, such as pine and broadleaved stands, it can be seen that the $\mathrm{Li}$ DAR-derived centerline was detected without problem in the pine forest area but disappears or is interrupted in the part bordered by broadleaved trees.

In reforested stands however, the percentage of LiDAR-derived centerlines detected was high, since the relatively recently planted vegetation was not very dense and did not occlude the centerlines of the roads. However, the number of false positives in these areas was also high, because the presence of bare soil among the trees gives rise to high intensity values, and the classification algorithm has problems distinguishing soil between lines of smaller young trees from the surface of the road. According to the results of Beck et al. (2015), differences in canopy cover proved to be a weakness in the road extraction process, which requires relative consistency of cover type to define intensity thresholds. Extreme differences in cover type throughout an area will have a large impact on results of the road extraction process. False positives in particular are more sensitive to these differences.

In this study, forest roads that did not have pronounced gradient were difficult to identify, as can be observed in the bottom left corners of Fig. 4A and Fig. 4B where slope is around $20 \%$. This has also been documented by White et al. (2010) and Azizi et al. (2014). Areas of gentle gradient can also cause breaks in the continuity of the forest roads network when drawing the centerline (Ferraz et al. 2014).

\section{Assessment of positional accuracy of LiDAR-derived centerlines}

The results of the assessment of the positional accuracy of the LiDAR-derived centerlines obtained with the method of Goodchild \& Hunter (1997) are shown in Fig. 6, which plots the percentage of the LiDAR-derived centerline lying within the buffer against buffer width for each approach, pixel-based (6A) and OBIA (6B).

Tab. 4 shows the positional accuracy of each approach in each of the sections examined, that is, the width of the buffer needed to encompass $95 \%$ of the field-survey centerline. In general, the pixel-based classification gave better results, especially in section $D$, where the accuracy difference between the two approaches was $4 \mathrm{~m}$. The higher accuracy in this section is due to the combination of two most favorable factors, big width (more than $4 \mathrm{~m}$ ) and surrounding vegetation composed by pines which was the kind of stand having the best behavior in terms of forest roads detection.

The average positional error was $\pm 5.50 \mathrm{~m}$ for the pixel-based approach and \pm 6.88 for OBIA. In the case of LiDAR-derived centerline accuracy, the fact that the pixel-based classification was more accurate may be related to the resolution of the images used in the classification process. According to Cánovas-García (2012), the object-oriented classification approach is capable of delivering more accurate results than those obtained by a pixel-based approach, especially when dealing with high spatial resolution images. However, in this case the resolution of the information layers involved in the detection of forest roads was not high because of the low density of the data used, and this may have counteracted the

Tab. 4 - Positional accuracy values (in meters) for the two approaches for each section.

\begin{tabular}{cclcccc}
\hline Section & $\begin{array}{c}\text { Length } \\
(\mathrm{m})\end{array}$ & $\begin{array}{l}\text { Road } \\
\text { surface }\end{array}$ & $\begin{array}{c}\text { Road } \\
\text { width }(\mathrm{m})\end{array}$ & Vegetation & Pixel & OBIA \\
\hline A & 994.3 & Aggregate & $2-4$ & Pine & 7.00 & 10.00 \\
B & 809.2 & Dirt & $2-4$ & Pine & 5.50 & 5.50 \\
\hline
\end{tabular}

difference found by Cánovas-García (2012). In addition, Cowen et al. (1995) highlight the fact that the object to be identified must be composed of at least 4 pixels if remote sensor images are used, a condition which was not always met in this study. As a result, the advantage of OBIA methods over pixel-based methods, that is the ability to generalize and reduce heterogeneity, becomes a drawback with low density data. Finally, much of the study area has a high degree of slope and dense vegetation which, together with the narrower width of some of the forest roads and the low resolution of the information layers, makes it difficult to create objects that are representative of roads in the segmentation process.

Comparing the results obtained in this study with other similar works, accuracy values are lower than those obtained by White et al. (2010) and Azizi et al. (2014) (1.3 and $1.2 \mathrm{~m}$ respectively). This may be due in large part to the low density of the LiDAR data used in this study ( 0.5 points $\mathrm{m}^{-2}$ vs. 12 and 4 points $\mathrm{m}^{-2}$, respectively) which forces the slope map and the intensity image to have a low resolution compared to the images used in the abovementioned papers. Morever, forest roads width in both these studies is, on average, of White et al. (2010), the process of digitizing the centerline was manual, while in this study it was completely automatic. Although this introduces a certain degree of error, it has the great advantage that it can be applied to large areas at very low cost. For example, Gao \& Wu (2004) report that the automatic extraction of road network information involves significantly less time and expense, though it is methodologically more complex. Doucette et al. (2009) defines productivity in relation to digitization of data as being the time taken to digitize greater than that in this study. In the case 
the information per measure of area. Roman et al. (2017) in an area with similar characteristics to those of this study, found manual digitization to have a productivity of $1 \mathrm{~km}$ per minute. In contrast, the productivity of the semi-automatic process presented here is $1 \mathrm{~km}$ in $9.2 \mathrm{~s}$ (using a computer with $8 \mathrm{~GB}$ of RAM). Based on these data, the use of the proposed method allows productivity to be increased more than 6 fold with respect to the manual method. Moreover, the positional accuracy of $\pm 5.50 \mathrm{~m}$ obtained here is still much better than the $\pm 12 \mathrm{~m}$ obtained by USGS (United States Geological Survey) in their topographic maps, or the $\pm 10 \mathrm{~m}$ used in traditional data sources to plot roads on the 1:25.000 topographic maps in Iran (Azizi et al. 2014). It is also very similar to the \pm $5 \mathrm{~m}$ positional accuracy of the mapping of the Spanish public road network, demonstrating that even the low density data used in this work can provide estimations as good as, and often better than, existing cartographies.

One final point to note is that forestry road extraction is typically a manual process where positional error depends on a number of factors, but the human factor (i.e., differences depending on the person making the digitization) has been reported to be approximately 3 meters (Doucette et al. 2009). As such, one of the main advantages of automatic vectorization techniques is that the effect of the individual disappears, and hence accuracy error depends only on the data sources and the vectorization methodology. Finally, if mapping were conducted over larger extents (hundreds to thousands of square kilometers) automated and semi-automated road extraction techniques could offer substantial savings in terms of time (Doucette et al. 2009).

\section{Conclusions}

In this study a methodology for the detection and extraction of forest roads from freely available LiDAR data of low density was designed and applied. The results obtained confirm the initial hypothesis that it is possible to semi-automatically reconstruct the forest roads network even in steep forested environments. As the analysis procedure has been implemented in a GIS Model Builder, it can be applied quickly and easily in other forest areas with similar or less complex and challenging characteristics.

Of the two approaches evaluated, the pixel-based classification method yielded slightly better results than the OBIA one with regard to the quality measures and positional accuracy. The completeness, correctness, and quality values were $65 \%$, $90 \%$ and $60 \%$, respectively, compared to $59 \%, 93 \%$ and $56 \%$ obtained with OBIA. Despite this, the results of the ANOVA demonstrate that neither the methodology used nor the type of road surface had any significant influence on the detection and digitization of the road centerline, although road width and the type of surrounding vegetation do. In fact, the results indicate that low density LiDAR data is suitable for the detection and digitization of forest roads over large areas, especially those where forest roads are wider (over 4 $\mathrm{m}$ ) and are not surrounded by broadleaved stands. With respect to positional accuracy, the values obtained by pixel-based classification are on average, $1.38 \mathrm{~m}$ more accurate than those from the OBIA for each of the sections examined ( \pm 5.50 vs. \pm $6.88 \mathrm{~m}$, respectively). The value of $\pm 5.50 \mathrm{~m}$ can be considered acceptable given that traditional data sources used to plot roads have lower accuracy values than this.

Regarding the methodology limitations, future research should focus on both improving the effectiveness of image classification and achieving more defined and continuous lines (road centerlines) in adverse vegetation and slope conditions.

Finally, efforts at a national level by governments to capture higher cloud point density data on a country-wide level open the door to large-scale detection trials. In Spain, the data that will be captured in the future, within the framework of PNOA, will allow the methodology presented in this study to be used to develop a cartography of forest roads, including mountainous areas, which can be updated every time new data is released. However, in the meantime, the approaches described in this work offer a valuable first step towards such a complete large-scale database of forest roads networks.

\section{Acknowledgements}

This study was funded by the SCALyFOR project (R\&D Projects "Research Challenges", Spanish Ministry of Economy and Competitiveness). The authors would like to thank the Forestry Service of the Principality of Asturias (Spain) for providing the information used. Thanks also to Ronnie Lendrum for revising the English.

\section{References}

Abdi E, Sisakht SR, Goushbor L, Soufi H (2012). Accuracy assessment of GPS and surveying technique in forest road mapping. Annals of Forest Research 55 (2): 309-317. [online] URL: http://afrjournal.org/index.php/afr/article/viewF ile/68/97

Arora A, Pandey MK (2011). Transportation network model and network analysis of road networks. In: Proceedings of the " $12^{\text {th }}$ Esri India User Conference". Gurgaon (Haryana, India) 78 December 2011, pp. 9. [online] URL: http:// www.esri.in/ /media/esri-india/files/pdfs/event s/uc2011/papers/Infra_UCP002.pdf

Azizi Z, Najafi A, Sadeghian S (2014). Forest road detection using LiDAR data. Journal of Forestry Research 25: 975-980. - doi: 10.1007/s11676-0140544-0

Beck SJ, Olsen MJ, Sessions J, Wing MG (2015). Automated extraction of forest road network geometry from aerial LiDAR. European Journal of Forest Engineering 1: 21-33. [online] URL: http://dergipark.gov.tr/download/article-file/6o 118

Buján S, González-Ferreiro E, Reyes-Bueno F, Barreiro-Fernández L, Crecente L, Miranda D (2012). Land use classification from lidar data and ortho-images in a rural area. The Photogrammetric Record 27 (140): 401-422. - doi: 10.11 11/j.1477-9730.2012.00698.x

Cánovas-García F (2012). Análisis de imágenes basado en objetos (OBIA) y aprendizaje automático para la obtención de mapas de coberturas del suelo a partir de imágenes de muy alta resolución espacial: aplicación en la Unidad de Demanda Agraria $n^{\circ} 28$, cabecera del Argos [Object-based image analysis (OBIA) and automatic learning for obtaining land cover maps from very high spatial resolution images: application in the Agrarian Demand Unit No. 28, head of the river Argos]. PhD thesis, Geography Department, University of Murcia, Murcia, Spain, pp. 204. [in Spanish] [online] URL: http:// www.aet.org.es/revistas/revista38/Numero38_ 12.pdf

Clode S, Rottensteiner F, Kootsookos P, Zelniker $E$ (2007). Detection and vectorization of roads from lidar data. Photogrammetric Engineering and Remote Sensing 73 (5): 517-535. - doi: 10.143 58/PERS.73.5.517

Comaniciu D, Meer P (2002). Mean shift: a robust approach toward feature space analysis. IEEE Transactions on Pattern Analysis and Machine Intelligence 24 (5): 603-619. - doi: 10.1109/ 34.1000236

Cowen DJ, Jensen JR, Bresnahan PJ, Ehler GB, Graves D, Huang X, Wiesner C, Mackey HE (1995). The design and implementation of an integrated geographic information system for environmental applications. Photogrammetric Engineering and Remote Sensing 61: 1393-1404. Craven M, Wing MG (2014). Applying airborne LiDAR for forested road geomatics. Scandinavian Journal of Forest Research 29: 174-182. - doi: 10.1080/02827581.2014.881546

Dial G, Gibson L, Poulsen R (2001). IKONOS satellite imagery and its use in automated road extraction. In: "Automatic Extraction of ManMade Objects from Aerial and Space Images (III)" (Baltsavias EP, Gruen A, Van Gool L eds). Swets and Zeitlinger, Lisse, The Netherlands. pp. 367. [online] URL: http://books.google. com/books?id=kjl4k58eOl4C

DGDRPF (2012). Fourth national forest inventory, Asturias. General Directorate of Rural Development and Forest Policy, Ministry of Agriculture, Food and Environment, Madrid, Spain, pp. 58. Doucette P, Grodecki J, Clelland R, Hsu A, Nolting J, Malitz S, Kavanagh C, Barton S, Tang M (2009). Evaluating automated road extraction in different operational modes. In: Proceedings of the Conference "Algorithms and Technologies for Multispectral, Hyperspectral, and Ultraspectral Imagery XV". Orlando (FL, USA) 14-16 Apr 2009. SPIE Defense, Security, and Sensing, vol. 7334, no. 73341A. - doi: 10.1117/12.817740 Edgeworth FY (1908). On the probable errors of frequency-constants. Journal of the Royal Statistical Society 71 (2): 381-397. - doi: 10.2307/23 39461

Ferraz A, Mallet C, Chehata N (2014). Large scale road network extraction in forested mountainous areas using airborne laser scanning data. 
In: Proceedings of the: "IEEE Geoscience and Remote Sensing Symposium". Québec (Canada) 13-19 July 2014, pp. 4315-4318. [online] URL: http://ieeexplore.ieee.org/xpls/abs_all.jsp? arnumber $=6947444$

Gao J, Wu L (2004). Automatic extraction of road networks in urban areas from IKONOS imagery based on spatial reasoning. In: Proceedings of the " $20^{\text {th }}$ ISPRS Congress". Istanbul (Turkey) 12-23 July 2004, pp. 12-24. [online] URL: http://cartesia.org/geodoc/isprs2004/com $\mathrm{m} 3 /$ papers/290.pdf

García M, Riaño D, Chuvieco E, Danson FM (2010). Estimating biomass carbon stocks for a Mediterranean forest in central Spain using LiDAR height and intensity data. Remote Sensing of Environment 114 (4): 816-830. - doi: 10.1016/j. rse.2009.11.021

González-Ferreiro E, Diéguez-Aranda U, Miranda D (2012). Estimation of stand variables in Pinus radiata D. Don plantations using different $\mathrm{Li}$ DAR pulse densities. Forestry 85: 281-292. - doi: 10.1093/forestry/cpsoo2

Goodchild MF, Hunter GJ (1997). A simple positional accuracy measure for linear features. International Journal of Geographical Information Science 11 (3): 299-306. - doi: 10.1080/13658 8197242419

Grigolato S, Pellegrini M, Cavalli R (2013). Temporal analysis of the traffic loads on forest road networks. iForest - Biogeosciences and Forestry 6 (4): 255-261. - doi: 10.3832/iforo773-006 Gruen A, Li H (1997). Linear feature extraction with 3-D LSB-snakes. In: "Automatic Extraction of Man-Made Objects from Aerial and Space Images (II). Monte Verità (Proceedings of the Centro Stefano Franscini Ascona)" (Gruen A, Baltsavias EP, Henricsson $O$ eds). Birkhäuser, Basel, Switzerland, pp. 287-298. - doi: 10.1007/9 78-3-0348-8906-3_28

Heinimann HR (1998). A computer model to differentiate skidder and cable-yarder based road network concepts on steep slopes. Journal of Forest Research 3 (1): 1-9. - doi: 10.1007/BF027 60286

Heipke C, Mayer H, Wiedemann C, Jamet O (1997). Evaluation of automatic road extraction. International Archives of Photogrammetry and Remote Sensing 32: 151-160. - [online] URL: http://citeseerx.ist.psu.edu/viewdoc/sum mary?doi=10.1.1.30.7686

Höhle J, Höhle M (2009). Accuracy assessment of digital elevation models by means of robust statistical methods. ISPRS Journal of Photogrammetry and Remote Sensing 64 (4): 398406. - doi: 10.1016/j.isprsjprs.2009.02.003

Hu H, Ding Y, Zhu Q, Wu B, Lin H, Du Z, Zhang Y (2014). An adaptive surface filter for airborne laser scanning point clouds by means of regularization and bending energy. ISPRS Journal of Photogrammetry and Remote Sensing 92: 98111. - doi: 10.1016/j.isprsjprs.2014.02.014

James LA, Watson DG, Hansen WF (2007). Using LiDAR data to map gullies and headwater streams under forest canopy: South Carolina, USA. Catena 71 (1) : 132-144. - doi: 10.1016/j.cate na.2006.10.010

Kiss K, Malinen J, Tokola T (2016). Comparison of high and low density airborne LiDAR data for forest road quality assessment. ISPRS Annals of Photogrammetry, Remote Sensing and Spatial Information Sciences III-8: 167-172. - doi: 10.519 4/isprsannals-III-8-167-2016

Kraus K, Pfeifer N (1998). Determination of terrain models in wooded areas with airborne laser scanner data. ISPRS Journal of Photogrammetry and Remote Sensing 53 (4): 193203. - doi: 10.1016/S0924-2716(98)00009-4

LIDAR-PNOA (2012). Sistema cartográfico nacional [National cartographic system]. Instituto Geográfico Nacional, Comunidades Autónomas de Cantabria, País Vasco / Euskadi y Comunidad Foral de Navarra, Spain. [in Spanish]

McGauhey RJ (2009). FUSION/LDV: a software for LiDAR data analysis and visualization. USDA Forest Service, Pacific Northwest Research Station, Seattle, WA, USA.

Mena JB (2006). Automatic vectorization of segmented road networks by geometrical and topological analysis of high resolution binary images. Knowledge-Based Systems 19: 704-718. - doi: 10.1016/j.knosys.2006.05.008

Narwade R, Musande V (2014). Automatic road extraction from airborne LiDAR: a review. International Journal of Engineering Research and Applications 4: 54-62. [online] URL: http://pdfs. semanticscholar.org/fe3o/c432b9f68f6391a58b 73f563daec9dee036e.pdf

Roman A, Ursu TM, Farcas S, Lazarescu VA, Opreanu CH (2017). An integrated airborne laser scanning approach to forest management and cultural heritage issues: a case study at Porolissum, Romania. Annals of Forest Research 60: 127-143. [online] URL: http://www. afrjournal.org/index.php/afr/article/viewFile/75 $5 / 638$

Saito M, Goshima M, Aruga K, Matsue K, Shuin Y, Tasaka T (2013). Study of automatic forest road design model considering shallow landslides with LiDAR data of Funyu experimental forest. Croatian Journal of Forest Engineering 34: 1-15. [online] URL: http://hrcak.srce.hr/116724?lang= en

Sherba J, Blesius L, Davis J (2014). Object-based classification of abandoned logging roads under heavy canopy using LiDAR. Remote Sensing 6 (5): 4043-4060. - doi: 10.3390/rs6054043

Sithole G, Vosselman G (2004). Experimental comparison of filter algorithms for bare-Earth extraction from airborne laser scanning point clouds. ISPRS Journal of Photogrammetry and Remote Sensing 59 (1-2): 85-101. - doi: 10.1016/ j.isprsjprs.2004.05.004

Song $M$, Civco D (2004). Road extraction using SVM and image segmentation. Photogrammetric Engineering and Remote Sensing 70 (12): 1365-1371. - doi: 10.14358/PERS.70.12.1365

Tveite $H$ (1999). An accuracy assessment method for geographical line data sets based on buffering. International Journal of Geographical Information Science 13 (1): 27-47. - doi: 10.1080/1365 88199241445

White RA, Dietterick BC, Mastin T, Strohman R (2010). Forest roads mapped using LiDAR in steep forested terrain. Remote Sensing 2 (4): 1120-1141. - doi: 10.339o/rs2041120

Wiedemann C, Heipke C, Mayer H, Hinz S (1998a). Automatic extraction and evaluation of road networks from MOMS-2P imagery. International Archives of Photogrammetry and Remote Sensing 32: 285-291. - doi: 10.3390/rs20 41120

Wiedemann C, Heipke C, Mayer H, Jamet O (1998b). Empirical evaluation of automatically extracted road axes. Empirical Evaluation Techniques in Computer Vision, pp. 172-187. [online] URL: http://citeseerx.ist.psu.edu/viewdoc/dow nload?doi=10.1.1.57.5701\&rep=rep1\&type=pdf 